УДК 621.396 .96

\title{
Reduce Radar Visibility Fighter \\ in Its Airborne Radar on the Emission and Maintenance of Enemy Electronic Intelligence
}

\author{
Alexander V. Bogdanova, Sergey S. Korotkova, \\ Denis V. Zakomoldin ${ }^{\mathrm{a}}$ and Igor V. Lyutikov*b \\ ${ }^{a}$ VKO Military Academy \\ named Marshal of the Soviet Union Georgiy Zhukov \\ 50 Zhigareva Str., Tver, 170100, Rssia \\ ${ }^{b}$ Siberian Federal University \\ 79/10 Svobodny, Krasnoyarsk, 660041, Russia
}

Received 21.11.2015, received in revised form 14.01.2016, accepted 09.03.2016

This article is one of the possible ways to reduce radar visibility fighter in the functioning of its on-board radar and airborne radar of the enemy on the emission and maintenance of their electronic intelligence.

Keywords: radar visibility, onboard radar, onboard, airborne, radiation, electronic intelli-gence.

Citation: Bogdanov A.V., Korotkov S.S., Zakomoldin D.V., Lyutikov I.V. Reduce radar visibility fighter in its airborne radar on the emission and maintenance of enemy electronic intelligence, J. Sib. Fed. Univ. Eng. technol., 2016, 9(3), $442-447$. DOI: 10.17516/1999-494X-2016-9-3-442-447.

(C) Siberian Federal University. All rights reserved

* Corresponding author E-mail address: lyutikovigor@mail.ru 


\title{
Снижение радиолокационной заметности истребителя
} при работе его бортовой радиолокационной станции

на излучение и при ведении противником

радиотехнической разведки

\author{
А.В. Богданов ${ }^{a}$, С.С. Коротков ${ }^{a}$, \\ Д.В. Закомолдин ${ }^{\mathrm{a}}$, И.В. Лютиков ${ }^{\sigma}$ \\ ${ }^{a}$ Военная академия ВКО \\ имени маршала Советского Союза Г.К. Жукова \\ Россия, 170100, Тверь, ул. Жигарева, 50 \\ ${ }^{6}$ Сибирский федеральный университет \\ Россия, 660041, Красноярск, пр. Свободный, 79/10
}

\begin{abstract}
В данной статье приводится один из возможных путей снижения радиолокационной заметности истребителя при функиионировании его бортовой радиолокационной станции, а также бортовой радиолокационной станции противника на излучение и при ведении им радиотехнической разведки.
\end{abstract}

Ключевые слова: радиолокачионная заметность, бортовой радар, бортовая, излучение, радиотехническая разведка.

Известны [1, 2] широкомасштабные экспериментальные исследования по оценке эффективности снижения радиолокационной заметности (РЛЗ) истребителей семейства Су27 за счёт уменьшения их эффективной площади рассеяния (ЭПР) на основе применения специальных покрытий и материалов. В результате экспериментов было установлено, что использование специальных покрытий и материалов позволит снизить ЭПР истребителя семейства Су-27 в среднем до 1 м². Несомненно, что полученные результаты открывают новые перспективы снижения РЛЗ истребителей на основе применения специальных покрытий и материалов. Однако их эффективность может быть существенно снижена в случае функционирования бортовой радиолокационной станции (БРЛС) истребителя на излучение при обнаружении воздушной цели, оснащённой станцией радиотехнической разведки (РТР).

Цель работы - предложить один из возможных подходов снижения РЛЗ истребителя при одновременном функционировании его БРЛС и БРЛС противника на излучение и ведении противником РТР.

Известно [3], что, с одной стороны, дальность $\mathrm{D}_{\text {Брлс }}$ обнаружения цели - носителя станции РТР с помощью импульсно-доплеровской БРЛС определяется выражением

$$
D_{\text {БрлС }}=\sqrt[4]{\frac{2 \cdot P_{\text {брлс }} \cdot T_{\text {кн }} \cdot G_{\text {брлс }} \cdot S_{\mathrm{a}} \cdot \sigma_{\text {ртр }}}{(4 \pi)^{2} \cdot \alpha_{\text {п }} \cdot N_{0} \cdot R_{0}}},
$$

где $P_{\text {брлс }}$ - средняя излучаемая мощность передатчика; $T_{\text {кн }}$ время когерентного накопления сигнала в приёмнике, равное времени облучения воздушной цели - носителя станции РТР; $G_{\text {брлс }}-$ коэффициент направленного действия передающей антенны; $S_{\mathrm{a}}-$ эффективная площадь приёмной антенны; $\sigma_{\text {ртр }}$ - ЭПР воздушной цели - носителя станции РТР; $\alpha_{n}-$ коэффициент 
потерь энергии сигнала при его обработке; $N_{0}$ - спектральная плотность внутренних шумов приёмника; $R_{0}$ - отношение энергии сигнала к спектральной плотности шума, при котором обеспечивается обнаружение воздушной цели - носителя станции РТР с заданной вероятностью.

С другой стороны, максимальная дальность обнаружения $D_{\text {Ртр }}$ станцией РТР излучённого БРЛС высокочастотного зондирующего сигнала определяется выражением

$$
D_{\text {РТР }}=\sqrt{\frac{P_{\text {брлс }} \cdot G_{\text {брлс }} \cdot G_{\text {ртр }} \cdot \lambda_{\text {брлс }}{ }^{2}}{(4 \pi)^{2} P_{\text {ртр }}}},
$$

где $G_{\text {ртр }}$ - коэффициент направленного действия приёмной антенны станции РТР; $\lambda_{\text {брлс }}$ длина волны БРЛС истребителя; $P_{\text {ртр }}$ - максимальное значение чувствительности приемника станции PTP [2].

При этом возможны две ситуации. Первая ситуация, когда дальность обнаружения станцией РТР излучённого сигнала БРЛС истребителя превышает или равна дальности обнаружения БРЛС истребителя - носителя станции РТР, т. е. $\mathrm{D}_{\text {Ртр }} \geq \mathrm{D}^{(\text {(n) }}$ Брлс. Вторая ситуация, когда дальность обнаружения БРЛС истребителя воздушной цели - носителя станции РТР превышает дальность обнаружения станцией РТР излучённого БРЛС истребителя зондирующего сигнала,

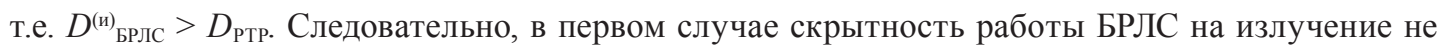
обеспечивается, а во втором - обеспечивается.

Поэтому для обеспечения постоянства скрытности работы БРЛС на излучение при обнаружении воздушной цели - носителя станции РТР необходимо выполнить условие

$$
D_{\text {БРЛС }}^{(u)}>D_{\text {РТР }},
$$

а для обеспечения того, чтобы БРЛС носителя станции РТР не обнаружила истребитель, дополнительно необходимо выполнить условие

$$
D^{(u)}{ }_{\text {БРЛС }}>D_{\text {БРЛС }}^{(\mu)} .
$$

На рис. 1 представлены результаты расчётов следующих зависимостей дальностей обнаружения от средней излучаемой мощности передатчиков БРЛС истребителя $P^{(\mathrm{n})}$ брлс и БРЛС носителя станции РТР $P_{\text {(н) }}^{(\text {брл }}$ при времени когерентного накопления 10 мс (соответственно зависимости 1 и 2):

БРЛС $D_{\text {(и) }}^{(\mathrm{s} л с ~ и с т р е б и т е л я ~ в о з д у ш н о и ̆ ~ ц е л и ~-~ н о с и т е л я ~ с т а н ц и и ~ Р Т Р ; ~}$

БРЛС носителя станции РТР истребителя $D^{(\mathrm{r})}$ Брлс;

станцией РТР ( $\left.D_{\text {Ртр }}\right)$ излучённого сигнала БРЛС истребителя (зависимость 3 ),

рассчитанные соответственно по формулам (1) и (2) при следующих типичных исходных данных.

Для расчёта дальности $D_{\text {Брлс }}^{(\mathrm{n})}$ обнаружения ((1) БРЛС истребителя воздушной цели - носителя станции РТР:

$$
G_{\text {брлс }}=6200 ; S_{\mathrm{a}}=0,79 \mathrm{M}^{2} ; \sigma_{\text {ртр }}=9 \mathrm{M}^{2} ; \alpha_{\mathrm{I}}=1 ; N_{0}=410^{-21} \text { Вт } / Г ц ; R_{0}=13 д Б .
$$

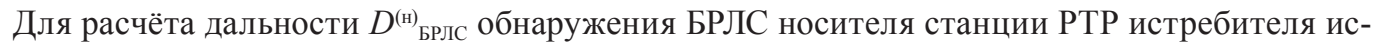
ходные данные такие же, что и для расчёта дальности $D^{(\text {) }}{ }_{\text {Брлс, }}$ за исключением ЭПР истребителя $\sigma_{\text {и }}=1 \mathrm{M}^{2}$. 
Для расчёта дальности $D_{\text {Ртр }}$ обнаружения (формула (2) станцией РТР излучённого БРЛС сигнала:

$$
G_{\text {ртр }}=80 ; \lambda_{\text {брлс }}=4 \mathrm{cM} ; P_{\text {ртр }}=-80 \text { ББ. }
$$

В табл. 1 приведены численные значения дальностей, показывающие положительный эффект при обеспечении полной скрытности истребителя при работающей его БРЛС на излучение.

Из приведённых графиков (рис. 1) следует, например, что при равных излучаемых мощностях БРЛС истребителя и БРЛС носителя станции РТР $\mathrm{P}_{\text {Брле }}^{(\mathrm{r}}=\mathrm{P}_{\text {Брлс }}^{(\mathrm{r})}=700$ Вт в случае равенства ЭПР истребителя и носителя станции РТР 9 м $^{2}$, дальности обнаружения $\mathrm{D}_{\text {Брлс }}^{(\mathrm{n})} \mathrm{D}_{\text {(н) }}^{(\mathrm{s} л с}$ равны и составляют около 500 км (зависимость 2).

Если предположить, что в результате применения специальных покрытий и материалов ЭПР истребителя будет снижена до $1 \mathrm{M}^{2}$, то дальность обнаружения истребителя с помощью БРЛС носителя станции РТР $\mathrm{D}^{(\mathrm{r})}$ Брлс уменьшится до 290 км (зависимость 1) по сравнению с оставшейся на прежнем уровне дальностью (500 км) обнаружения $\mathrm{D}^{(\mathrm{n})}$ Брлс истребителем носителя станции РТР, т.е. условие (4) будет выполняться. Однако ввиду работы БРЛС истребителя на излучение противник с помощью станции РТР, установленной на его борту, обнаружит истребитель Су-27, несмотря на принятые меры по снижению его ЭПР. Так, согласно рис. 1, при той же излучаемой мощности $(700 \mathrm{BT})$ дальность обнаружения $\mathrm{D}_{\text {Ртр }}$ станцией РТР излучённого

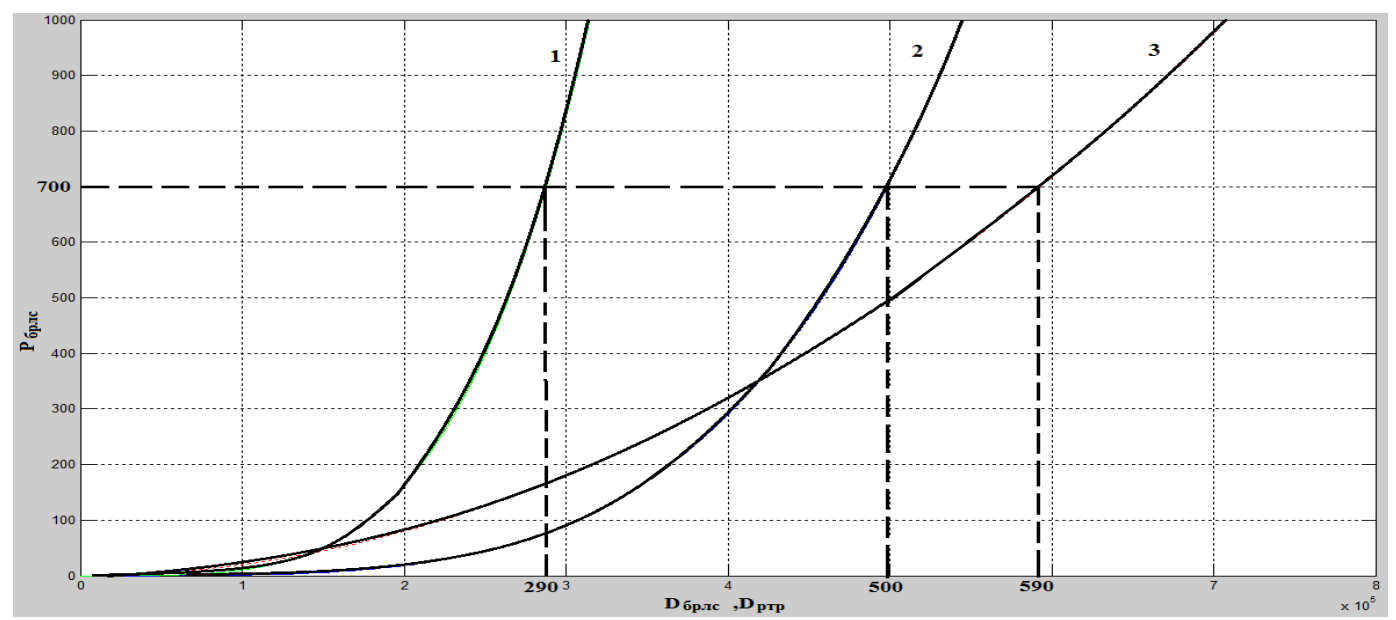

Рис. 1.

Таблица 1. Дальности обнаружения

\begin{tabular}{|c|c|c|c|c|}
\hline \multicolumn{2}{|c|}{$\begin{array}{l}\text { Параметры БРЛС истребителя } \\
\text { и БРЛС носителя станции РТР }\end{array}$} & \multicolumn{3}{|c|}{ Дальность обнаружения } \\
\hline$T_{\text {кн }}, \mathrm{MC}$ & $P_{\text {БрлС }}^{(\text {() }} / P_{\text {БРлС }}^{\text {(н) }}, \mathrm{BT}$ & $D_{\text {РТP, KM }}$ & $D_{\text {БРлС }}^{\text {(н) }}$, Км & $D_{\text {БРЛС }}^{\text {(и) }}$, КМ \\
\hline 10 & $700 / 700$ & 590 & 290 & 500 \\
\hline 20 & $350 / 700$ & 420 & 340 & 500 \\
\hline
\end{tabular}


сигнала БРЛС истребителя (зависимость 3) будет составлять 590 км (кривая 3) и существенно превышать дальность обнаружения с помощью БРЛС истребителя $\mathrm{D}^{(\text {() }}$ Брлс носителя станции РТР (500км), т.е. условие (3) выполняться не будет и, соответственно, в целом скрытность истребителя и работы его БРЛС обеспечена не будет.

Поэтому предлагается одновременно увеличить время когерентного накопления сигнала в приёмнике БРЛС истребителя и уменьшить излучаемую мощность её передатчика [5]. В качестве примера на рис. 2 дополнительно к зависимостям, отраженным на рис. 1 приведена зависимость 4, аналогичная зависимости 2 (рис. 1), но при времени когерентного накопления, увеличенном в 2 раза до 20 мс, в БРЛС истребителя (аналогично и в БРЛС носителя станции РТР) время когерентного накопления также увеличено в 2 раза - до 20 мс (зависимость 1).

При этом если излучаемую мощность передатчика уменьшить также в 2 раза до $P^{(\text {() }}$ БрлС $=350$ Вт, то при неизменной излучаемой мощности передатчика БРЛС носителя станции РТР $P_{\text {(н) }}^{(\text {Брлс }}=700$ Вт дальность обнаружения БРЛС истребителя носителя станции РТР останется на прежнем уровне $-D^{(\text {() }}$ Брлс $=500$ км (зависимость 4), дальность обнаружения истребителя БРЛС носителя станции РТР также увеличится до $D_{\text {(и) }}^{\text {врлС }}=340$ км (зависимость 1), а дальность обнаружения станцией РТР излучённого сигнала БРЛС истребителя с 590 км уменьшится до $D_{\text {Ртр }}=420$ км (зависимость 3), т.е. одновременно будут выполнены условия (3) и (4), что является свидетельством полного обеспечения скрытности истребителя при работающей его БРЛС на излучение

Таким образом, путём комплексного применения специальных покрытий и материалов для снижения ЭПР истребителя и увеличения времени когерентного накопления сигнала в его БРЛС при одновременном уменьшении средней излучаемой мощности передатчика можно обеспечить полную скрытность истребителя при его работающей БРЛС на излучение и ведении со стороны противника радиотехнической разведки.

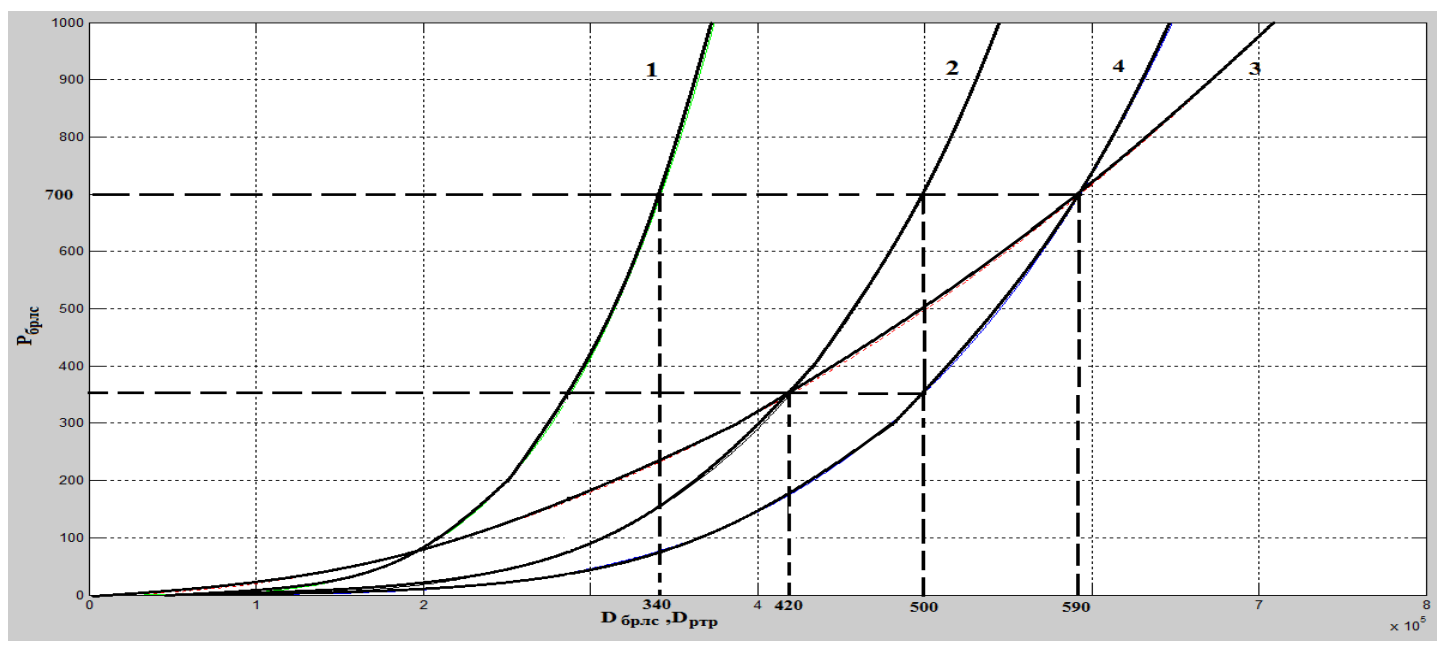

Рис. 2. 


\section{Список литературы}

[1] Богданов А.В., Васильев О.В., Коротков С.С., Мазуркин А.В. Методика экспериментальных исследований по оценке эффективности снижения радиолокаиионной заметности истребителей семейства Су-27. Научно-методический сборник. Тверь: НИЦ ЦНИИ ВВКО, 2014. [Bogdanov A.V., Vasil'ev A.V., Korotkov S.S., Mazurkin A.V. Methods of experimental studies evaluating the efficacy of reducing the radar visibility of fighters Su-27. Scientific methodical collection. Tver: Central Research Institute of Air and Space Defense, 2014.]

[2] Богданов А.В., Васильев О.В., Коротков С.С., Мазуркин А.В. Экспериментальная оценка эффективности мероприятий по снижению эффективной площади рассеяния отдельных элементов конструкции истребителей семейства Су-27. Научно-методический сборник. Тверь: НИЦ ЦНИИ ВВКО, 2014. [Bogdanov A.V., Vasil'ev O. V., Korotkov S.S., Mazurkin A.V. Experimental assessment of efficiency of actions for decrease in the effective area of dispersion of separate elements of a design of fighters of Su-27 family. Scientific and methodical collection. Tver: Central Research Institute of Air and Space Defense, 2014.]

[3] П.И. Дудник, Г.С. Кондратенков, Б.Г. Татарский, А.Р. Ильчук, А.А. Герасимов. Авиационные радиолокационные комплексы и системы: учебник для слушателей и курсантов ВУЗов ВВС. Под ред. П.И. Дудника. М.: Взд. ВВИА им. проф. Н.Е. Жуковского, 2006. [Dudnik P. I., Kondratenkov G. S., Tatar B.G., Ilchuk A.R., Gerasimov A.A. Aviation radar complexes and systems: the textbook for listeners and cadets of higher education institutions of the Air Force. Under the editorship of P. I. Dudnik. M.: Prod. VVIA of the prof. N. E. of Zhukovsky, 2006.]

[4] Белоцерковский Г.Б. Основы радиолокации и радиолокационные устройства. М.: «Сов. Радио», 1975, с. 96. [Belotserkovskiy G.B. Fundamentals of radar and radar devices. M.: "Sov. Radio", 1975, p. 96].

[5] Гуськов Ю., Антипов В., Колтышев Е. Принципы построения многофункииональных радиолокационных комплексов. Информационно аналитический журнал «Радиоэлектронные технологии». 2015, 1, 120 c. [Guskov Yuri Antipov VA, Koltyshev E. Principles of multifunction radar complexes. Information and analytical magazine "Radio-electronic technologies», 2015, 1, 120 p.] 